\title{
Why COVID-19 is less frequent and severe in children: a narrative review
}

\author{
Reza Sinaei $^{1} \cdot$ Sara Pezeshki ${ }^{2}$ (D) Saeedeh Parvaresh ${ }^{1} \cdot$ Roya Sinaei $^{1}$
}

Received: 19 May 2020 / Accepted: 8 September 2020 / Published online: 25 September 2020

(c) Children's Hospital, Zhejiang University School of Medicine 2020

\begin{abstract}
Background Despite the streaks of severity, severe acute respiratory syndrome-coronavirus-2 (SARS-CoV-2) infection is, in general, less frequent and severe in children than in adults. We searched for causal evidence of this mystery.

Data sources An extensive search strategy was designed to identify papers on coronavirus disease 2019 (COVID-19). We searched Ovid MEDLINE, PubMed, EMBASE databases, and Cochrane library and carried out a review on the causes of this dilemma.

Results Our searches produced 81 relevant articles. The review showed that children accounted for a lower percentage of reported cases, and they also experienced less severe illness courses. Some potential explanations, including the tendency to engage the upper airway, the different expression in both receptors of angiotensin-converting enzyme and renin-angiotensin system, a less vigorous immune response, the lower levels of interleukin (IL)-6, IL-10, myeloperoxidase, and P-selectin and a higher intracellular adhesion molecule-1, a potential protective role of lymphocytes, and also lung infiltrations might have protective roles in the immune system-respiratory tract interactions. Finally, what have shed light on this under representation comes from two studies that revealed high-titer immunoglobulin-G antibodies against respiratory syncytial virus and mycoplasma pneumonia, may carry out cross-protection against SARS-CoV-2 infection, just like what suggested about the vaccines.

Conclusions These results require an in-depth look. Properties of the immune system including a less vigorous adaptive system beside a preliminary potent innate response and a trained immunity alongside a healthier respiratory system, and their interactions, might protect children against SARS-CoV-2 infection. However, further studies are needed to explore other possible causes of this enigma.
\end{abstract}

Keywords Children · Coronavirus disease $2019 \cdot$ Severe acute respiratory syndrome-coronavirus 2

\section{Introduction}

The novel coronavirus infection spread rapidly, so that the World Health Organization (WHO) declared this epidemic as a pandemic on March 11, 2020 [1]. According to the

Sara Pezeshki

s.pezashki@kmu.ac.ir; sarapezeshki83@gmail.com

1 Department of Pediatrics, School of Medicine, Endocrinology and Metabolism Research Center, Institute of Basic and Clinical Physiology Sciences, Kerman University of Medical Sciences, Kerman, Iran

2 Department of Internal Medicine, School of Medicine, Endocrinology and Metabolism Research Center, Institute of Basic and Clinical Physiology Sciences, Kerman University of Medical Sciences, Kerman, Iran preliminary data, the overall case fatality rate is about $2.3 \%$ and is significantly higher in older patients [2]. Also, hospitalization rate increases with age, given the increased risk of nasal colonization and secondary infections [3, 4]. Limited initial data exist on the burden of coronavirus disease 2019 (COVID-19) in children [5]. Thus far, only a small number of severe acute respiratory syndrome-coronavirus 2 (SARS$\mathrm{CoV}-2$ ) infection have involved children, so that they have accounted for only $1-5 \%$ of total patients $[2,6-10]$. However, doubt has existed as to whether COVID-19 is really less common in children, and some have believed that children are as likely as adults to become infected, but are less likely to be symptomatic or to develop severe symptoms [11]. Some have attributed this to a lack of real epidemiological studies in children. However, the recent epidemiological studies have shown that although children are more likely to be affected than those 
reported previously, children are still less likely to be affected than adults. In Iceland, researchers screened $6 \%$ of country's population and found that children under 10 years of age had a lower incidence of SARS-CoV-2 infection than adults [12]. Although similar epidemiological results, especially those from serological investigations, are emerging in other countries, such as the Netherlands, Australia, and China, researchers in China found that children were less likely to catch the COVID-19 within households from an affected family member [13]. Similarly, of 806 close contacts in 15 schools in Australia, only two students have been identified as secondary cases [14]. However, these are three ways that researchers have gauged whether children are less frequently infected by SARS-CoV-2 infection. The available data also suggest that SARS-CoV-2 is less severe in children. In a report, among 149,082 cases reported in the United States through April 2, 2020, children experienced less severe symptoms. Fever, cough, or shortness of breath were in $73 \%$ of children compared to $93 \%$ of adults. Also, myalgia, sore throat, headache, and diarrhea were less commonly reported by pediatric patients. Three deaths were noted among the pediatric patients in this analysis. However, children aged less than 1 year accounted for the highest hospitalization [15]. Dong et al. investigated epidemiological characteristics of 2143 suspected pediatric patients. Infection was confirmed in $34 \%$ of these patients, whereas $94.1 \%$ of them were asymptomatic, or had mild to moderate courses, and $4.4 \%$ were asymptomatic [16]. These data were similar to previous findings that children with COVID-19 may not have reported fever, cough, or sore throat as often as adults [17]. Also, Dong et al. revealed that the prevalence of severe and critical disease was $10.6 \%$ in children aged less than 1 year, $7.3 \%$ in those aged $1-5$ years, $4.2 \%$ in those aged $6-10$ years, $4.1 \%$ in those aged 11-15 years, and 3\% in those aged 16-17 years [16]. However, some patients experienced severe courses of illness. Severe SARS-CoV-2 infection is characterized by a hyperproinflammatory response or cytokine storm state that results to acute respiratory distress syndrome (ARDS) and multisystem inflammatory syndrome (MIS). ARDS is characterized by hypoxemic respiratory failure with bilateral lung infiltrates often necessitating invasive respiratory support. In contrast, this situation occurs less frequently in pediatric patients [18, 19]. In a systematic review of 7480 pediatric patients with confirmed COVID-19, only $2 \%$ were severe (e.g., dyspnea, central cyanosis, and hypoxemia), and $0.7 \%$ were critical (e.g., ARDS, respiratory failure, and shock) [20]. Unexpectedly, there is now a growing cognizance of small reports of pediatric patients with a hyper inflammatory response termed as MIS-C or Kawasaki-like disease [21, 22]. Nevertheless, these two entities are not so common, and the most children experience milder illness. For the first time, we reported two pediatric patients with reactive arthritis who presented with limping following SARS-CoV-2 infection [23]. The data on laboratory markers in children also revealed lower lymphocytopenia
(3-3.5\%) than adults (63\%) in several studies. Also, children generally had lower increased C-reactive protein and procalcitonin levels. Thus, the overall prognosis of the disease in children is relatively good [15, 17, 24-26]. Unfortunately, due to the high percentage of missing data, a real statistical evaluation and comparison could not be conducted [27]. However, it seems that symptoms in children are both less frequent and less severe. In this review, we comprehensively investigated the most likely causes of this enigmatic topic, although all the actual causes remain unclear.

\section{Search strategies}

An extensive search strategy was designed to identify all relevant papers from beginning to August 23, 2020. We used Ovid MEDLINE, PubMed, EMBASE, and Cochrane library and carried out a review on the causes of the lower prevalence and less severity of COVID-19 in pediatric patients. The search strategy was constructed based on searching terms 2019 novel coronavirus, COVID-19, SARS-CoV-2 with using and/or, also the terms of child, pediatric, newborn, infant, adolescence, adult, age, age groups, severity, epidemiology, prevalence, difference, immune system, etiology, reasons in title, abstract, and key words.

The data were screened and extracted independently by two investigators (the first and corresponding authors) and by one highly experienced librarian; then we proceeded to cross check the results. In addition, we increased the references by using an additional snowballing method. After discussion and consensus, the article was written. The inclusion criteria were: (1) children and adolescents $<19$ years of age; (2) all scientific papers and letters, about COVID-19; and (3) description of the possible causes of lower prevalence and less severity of diseases. The exclusion criterion is that of $\geq 19$ years of age.

The search found 994 papers. After removing the duplications and less relevant papers, 81 scientific papers and letters $(5-19,24-69,84-103)$ were included. However, several speculations were derived from pathophysiology of disease and defensive mechanisms. The results were categorized into two main groups of causes (immunological and non-immunological considerations), and each group included the six subsets described below. All causes are involved in the less severity of illness, but some (as *) include the simultaneous and parallel causes of less frequency.

\section{Immunological considerations}

\section{Children have a less vigorous immune response}

The first results stem from some considerations that children have a less vigorous immune response to the virus than adults 
because the cytokine storm is thought to be important in the pathogenesis of severe SARS-CoV-2 infections [28]. These results have been suggested from several studies in which elevated inflammatory markers are less common in children, so they experience milder disease than adults [29].

\section{Children have a more active innate immune response*}

Of course, this is not in conflict with another hypothesis that children have a more active innate immune response that can be one of the early stages of defense [11]. This can be attributed to the fact that children had more recurrences of recent viral infections [30]. However, if the disease went further extension, a less vigorous immune response may prevent them from the cytokine storm and help to reduce the severity.

\section{The immunosenescence phenomenon*}

Jeljeli et al. studied the ontogeny of cytokine production in the response of phytohemagglutinin by aging and found a rapid shift from enhanced interleukin (IL)-10 secretion capacity at birth toward balanced IL-10/T helper (Th) 1/ Th2/Th17 cytokine levels early in life. This change appears to be an essential precondition to fight pathogens and also avoids overwhelming inflammatory reactions [31]. Schouten et al. discovered an age-dependent difference in levels of biomarkers in the lungs of ARDS patients. Levels of IL-6, IL-10, myeloperoxidase, and P-selectin were higher by aging; whereas intercellular adhesion molecule-1 was higher in neonates [32]. However, immunosenescence also may be explain COVID-19 age variability. It refers to the gradual deterioration of the immune system (especially adaptive type) brought on by natural age advancement [33, 34]. Some studies revealed that with aging, there is a gradual decrease of naïve $T$ cell numbers related to the thymic changes, shrinkage in the collection of $\mathrm{T}$ cell clones generated in the thymus, and loss of costimulatory receptor CD28. All these factors may impair the immunological responses with age [35-37]. Shortening of telomeres, especially T cells with cell divisions, might be associated with impaired immune response to new antigens along with increasing the production of proinflammatory cytokines [38, 39]. Zhu et al. revealed that among 667 adolescents, the African and the girls had longer telomeres [40]. These findings along with those of other studies can justify the severity of COVID-19 in males and also by aging [41].

\section{The higher lymphocyte and natural killer cell counts in children ${ }^{*}$}

Some have suggested that the constitutional higher percentage of lymphocytes and natural killers (NK) in children may have a defensive role in COVID-19 [42]. Indeed, increasing proinflammatory cytokines associated with neutrophil function with age, associated with severity of ARDS and may explain, to some extent, the age-dependent difference [43]. In adult patients lymphocytopenia (especially CD4 + and CD8 + T lymphocytes) has been associated with increased severity or worse outcomes [44]. Total leukocyte and neutrophil counts and the neutrophil/lymphocyte ratio can be used as follow-up parameters in COVID-19 [45]. At least in three cohorts, the majority of pediatric patients had normal leukocytes and lymphocytopenia accounted for only 3-3.5\% of cases [17, 24, 25]. Given the central role of lymphocytes and monocytes in the induction of immune responses, their frequency in peripheral blood might be expected to reflect the state of an individual's immune response to infection [46]. In addition, since $T$ cells are required for controlling exuberant innate immune responses, the absence of a potent antivirus $\mathrm{T}$ cell response in aged hosts could lead to an exuberant response and damage, which is not seen in children [47, 48]. Wynn and colleagues found that 2360 genes in neutrophils, 965 in monocytes, and 109 genes in lymphocytes were up- or down-regulated in pediatric septic shock, referring the data that circulatory lymphocytes are not the main leukocytes population with altered gene profiles during septic shock [49].

\section{Children have more trained immunity after previous infections*}

Other results for a milder disease in children are linked to a trained immunity that represents an immune memory after antigen exposure [26]. Interestingly, what have shed light on this under representation comes from two studies that revealed multiple high-titer antibodies against respiratory syncytial virus (RSV) and Mycoplasma pneumoniae (MP) in the blood of children appears to offer cross protection against SARS-CoV-2 infection [50, 51]. Several studies have shown that children are more susceptible than adults to infection by RSV and MP [52-55]. MP has been reported in 10-40\% of community-acquired pneumonia cases, and children with 5-15 years age are the most susceptible groups. Although, this was documented in children under 4 years by the report of 2010-2011 of European epidemic data [54]. Also, RSV is more prevalent in infancy. The WHO has reported RSV as a causative pathogen for over 30 million new cases of lower respiratory infection episodes, including acute bronchitis in children less than 5 years age [52]. Older siblings are a greater source of spreading infection than adults because they spend significant time in nurseries and schools [55]. These events can train the immunity of children so that neutralizing cross-reactive antibodies of MP and RSV may be more common in children than in adults. In a retrospective review of all COVID-19 patients treated at Wuhan union 
hospital until March 20, 2020, Mi et al. evaluated the correlation between prior exposures to MP and better clinical response in COVID-19 patients. The immunoglobulin G $(\mathrm{IgG})$ positive patients had a higher lymphocyte, monocyte and eosinophil counts and percentages $(P<0.05)$ than COVID-19 patients without MP IgG. In addition, thrombin time and lactate dehydrogenases were better in this group. Furthermore, requirement and use of nasal catheter oxygen mask was significantly lower in COVID-19 patients with MP IgG positivity $(P=0.029)$. Their findings indicate that MP IgG positivity is a potential protective factor for SARSCoV-2 infection [51]. Orange et al. showed that the intravenous immunoglobulin (IVIG) manufactured from a plasma pool derived from high-titer, anti-RSV plasma donors contains high titers of antibodies to several common respiratory viruses (influenza A, B, human metapneumovirus, parainfluenza 1, 2, and 3, CoVOC42 and V299E); this study found a direct correlation between antibody responder status of donors to RSV and their responder status to other viruses $(P<0.05)$. Although, there are, however, a number of considerations, this could be due to higher humoral immune responders in general or especially against intercellular antigens, to diversity in major histocompatibility complex alleles, and finally to donors that might have experienced a greater diversity of viral infection. This can be generalized to the more infections in children and the potential protection effect that results from these infections [50].

\section{A trained immunity after previous vaccines*}

Cao and colleagues emphasized the role of trained immunity as a new immune model that represents a cross protection against various pathogens. It can be activated also by some vaccines, such as Bacillle Calmette-Guerin (BCG), by generation of immune memory just like what is seen in MP [26]. Miller and colleagues found that countries without universal policies of BCG vaccination (e.g., USA, Italy) have been affected more severely as compared to countries with universal and long-standing BCG policies. Also, countries that have a late start of universal BCG policy (e.g., Iran in 1984) had a high mortality, consistent with the idea that BCG protects the vaccinated elderly population. In addition, they found that BCG vaccination reduced the number of reported COVID-19 cases in the country. The combination of reduced mortality and morbidity makes BCG vaccine a potential new tool in the fight against COVID-19 [56]. However, this cross-protection has been considered, and what argues against this anecdotal assumption is the higher mortality of COVID-19 in countries where BCG vaccine is compulsory [47]. Myśliwska et al. investigated the relationship between NK activity in the vaccinated population and specific immune protection against influenza virus. They concluded that NK cells activation, which was still significantly elevated after 1 month of vaccination, may allow protection against influenza and other respiratory viral infections [57]. Indirect epidemiological analyses also have suggested a protective role of the Measles, Mumps, and Rubella vaccine against COVID-19 [58]. Because the majority of vaccinated individuals had not protective IgG titer against measles after 10 years, Hanker et al. hypothesized that age-dependent decline in immunogenicity against measles vaccine could be an explanation for the higher occurrence of COVID-19 in adults [59].

\section{Non-immunological considerations ${ }^{*}$}

There are several issues at this setting. The results show at least six other considerations including some constitutional and behavioral reasons: (1) available data suggest that children may have more upper respiratory tract involvement than the lower. Thereafter, viral interference in young children leads to a lower viral load [16]. However, several speculations have emerged at this setting. Young children generally, have a healthier respiratory machinery due to their lower exposure to harmful environmental factors. In addition, children have fewer underlying chronic diseases, than what seen in adults [11]; (2) possible reasons for the disparity in severity between adults and children may be related to the difference in distribution, maturation, and functioning of receptors of renin angiotensin system (RAS), angiotensinconverting enzyme 2 (ACE-2), and altered inflammatory response to virus [60]. Zhu et al. have looked for reasons of this disparity in severity [61]. ACE-2 is the receptor of viral endocytosis and also alters the RAS activity from proinflammatory to anti-inflammatory response [62]. The ACE levels may be altered by several underlying diseases [63] and by age [64] in a murine model, although Schouten and colleagues found that there is no marked difference in ACE and ACE-2 among age groups [32]. However, this speculation should be investigated; (3) Xie et al. believe that children are less likely to be exposed to the virus. This may be due to fewer outdoor activities and to less international travel. Also, Xie et al. considered an under-diagnosis of children that might have resulted from their milder symptoms and therefore yielded fewer laboratory tests [27]; (4) in Attili and colleague's investigation, age-stratified odds ratios showed that the nasal carriage was higher in adult rabbits [65]. This result suggested that the presence of the respiratory nasal bacterial colonization might have more impact in the adult population [49]. In contrast, it is possible that the presence of other viruses in the respiratory tract of young children limits the SARS-CoV-2 development by direct virus-virus interactions [66]. This hypothesis stems from the greater frequency of viral infection in children and also provides a link between the viral load and COVID-19 severity [52-55, 67]; 
(5) in total, some results suggest that children have specific mechanisms that regulate the interaction between their immunological and respiratory systems, which could be contributing to milder disease. As a result, lymphocytes have participated in the inducible bronchus associated lymphoid structure after that respiratory insult has happened [68]; (6) it was suggested that maturational changes in the axonal transport system may explain the relative resistance to immature mice to poliovirus induced paralysis [69]. This can be generalized to the issue as a complementary reason.

\section{Some exceptions and especial issues}

\section{Neonatal period and vertical transmission}

Knowledge about neonatal outcomes of SARS-CoV-2 infection is relatively limited. Immaturity of both innate and adaptive immune systems make this group highly vulnerable to infection [70]. Interestingly, the majority of neonates born to mother with COVID-19 were not infected, and to date few reports have suggested that neonates have been affected by COVID-19. The possible reasons might be related to surgical delivery and to rapid separation of neonate [71]. Levy found that neonatal antigen presenting cells and plasmacytoid dendritic cells have impaired production of interferon- $\gamma$ and present a bias against the production of Th1 cytokines [72]. However, the levels of IL-6, IL-10, myeloperoxidase, and P-selectin are higher by aging, whereas intercellular adhesion molecule-1 is higher in neonates [32]. Therefore, unlike the infants under 1 year that are at higher risk of infection and hospitalization (17.6\% of pediatric cases and $10.6 \%$ of critical cases) [16], neonates are less likely to be infected. In contrast, two known ACE- 2 and transmembrane protease serine- 2 receptors are widely spread in specific cell types of maternal-fetal interface and might be vulnerable to the neonate affecting by SARS-CoV-2 infection. However, on March 2020, the first case report of possible vertical transmission of SARS-CoV-2 infection was published [73]. Dong et al. speculated the possibility of maternal fetal transmission of virus by demonstrating a higher IgM level and abnormal cytokines 2 hours after birth [74]. However, two independent manuscripts described elevated SARS-CoV-2 specific IgM and IgG antibodies in the blood of newborns of affected mothers. To date, while maternal infections were observed in the late phase of pregnancy, there may not have been sufficient time for the generation of antibodies. Thus, serological investigation for the diagnosis of neonate is still controversial. Nevertheless, increased level of IgG could be explained by trans-placental transferring from infected mother, while IgM strongly indicates a selfimmune response of newborns $[74,75]$. Thus, the elevated IgM might suggest that neonate was infected in utero. In any case, the possibility of vertical transmission has been raised. After birth, the neonates might be involved. Zeng et al. reported a series of 33 infants from mothers with COVID-19, while three of whom were symptomatic, with a radiological picture of pneumonia. The 31 weeks neonate developed coagulopathy, associated with sepsis. None of the newborns died. The clinical features of infected newborns might be nonspecific and include acute respiratory distress syndrome, temperature instability, gastrointestinal, and cardiovascular dysfunction [76]. However, the age-dependent pattern of immune reactions and other physiological elements may influence the response to SARS-CoV-2 in the neonatal subpopulation [73].

\section{Some exceptions of severity}

Although COVID-19 in children appears largely to present with mild features, a very small percentage of children with SARS-CoV-2 infection experience MIS-C weeks later. However, the MIS-C cases usually do not primarily affect the lungs [77].

\section{Multisystem inflammatory syndrome and Kawasaki-like disease}

The recent reports from European countries and the US followed by growing universal reports support the emergence of this novel phenomenon [18]. The clinical presentations of this entity are variable and include persistent fever, severe illness, and involvement of two or more organ systems, in combination with laboratory evidence of both inflammation and SARS-CoV-2 infection. However, some presentations of MIS-C resemble Kawasaki disease (KD), toxic shock syndrome, and secondary hemophagocytic lymphohistiocytosis/macrophage activation syndrome [18, 19]. Of the 191 potential cases reported across 191 hospitals in New York State, 95 patients were classified as confirmed MIS-C. The peak in the number of MIS-C cases followed the peak in the number of cases of laboratory-confirmed SARS-CoV-2 infection by 31 days. The researchers stated that based on molecular and serological results, MIS-C is probably a post-infectious, inflammatory process related to COVID-19 [78]. Also, because the majority of patients have had positive serological results for SARS-CoV-2, with a lesser number of positive RT-PCR tests, this condition may be more a postinfection entity rather than one related to acute early infection state. This hypothesis seems to have emerged for two reasons. First, MIS-C cases lagged in time compared with the peak of SARS-CoV-2 infection. Second, children who were involved in MIS-C, more often have $\mathrm{IgG}$ than positive molecular tests. However, MIS-C is a delayed immunological response associated with inflammation characterized by elevated levels of proinflammatory cytokines 
including IL-6, IL-1 $\beta$, IL-17, TNF- $\alpha$, and granulocyte colony-stimulating factor. As a hypothesis, because the younger patients have increased number of naïve $T$ cells in different sites to respond to new pathogens [43], this may prevent severe respiratory disease in children. Thus, a low-level, persistent infection in other sites may accumulate over time in some children, resulting in MIS-C [19].

One compelling alternative hypothesis for this entity stems from the ability of coronaviruses to block type I and III of interferon responses, that can result from delayed hyper-inflammatory response in whom that have a high viral load or cannot to control the infection [79, 80].

A mapping systemic inflammation and antibody $(\mathrm{Ab})$ responses in MIS-C was conducted. They documented that all MIS-C patients had IgG against SARS-CoV-2 infection. They identified elevated signatures of inflammation (IL-18, IL-6), lymphocytic and myeloid chemotaxis and activation (CCL3, CCL4, and CUB domain-containing protein-1), and mucosal immune dysregulation (IL-17A, CCL20, CCL28). Also, a reduction in m-Dendritic cells, NK cells, and T cells in blood were seen, suggesting extravasation to affected tissues. Also, some disease-associated autoantibodies (antiLa) were seen. These results suggest that autoreactivity secondary to SARS-CoV-2 infection and the inflammatory innate immune response may be crucial to the pathogenesis of MIS-C [81]. Interestingly, Diorio et al. based on the clinical phenotype, hypothesized that children with MIS-C are presenting with a syndrome that is distinct from both KD and severe COVID-19 infection. The researchers found that the patients with MIS-C had elevated levels of TNF- $\alpha$ and IL-10, whereas patients with severe or mild COVID19 had no or minimally elevated levels of these cytokines. This profile for MIS-C is distinct from what happens in $\mathrm{KD}$, which is associated with mild elevations of other cytokines (IL-1, IL-2, and IL-6) and not IL-10. TNF- $\alpha$ appears to play key role in the pathogenesis of both MIS-C and KD. Viral cycle thresholds (Cts) and burr cells on blood smears also differentiated between patients with severe COVID-19 and MIS-C. The high Cts associated with MIS-C support a postinfectious etiology phenomenon that has previously been postulated but not demonstrated [18, 82]. However, children with MIS-C have no higher IL-10 level, and this may be due to their higher lymphocyte counts hypothetically. In addition, they showed distinct $\mathrm{Ab}$ responses as compared to adults with severe COVID-19 causing ARDS, and to those who recovered from mild disease. Patients with MIS-C, often generate $\mathrm{IgG}$ Abs specific for spike (S) protein, while adults with COVID-19 showed anti-S, IgM, and IgA Abs, as well as anti-N IgG Abs. Moreover, MIS-C patients had reduced neutralizing activity compared COVID-19 cohorts, indicating a reduced protective serological response [19]. These results suggest a distinct infection course and immune response in children and adults with severe disease.
Children appear to have a less severe pulmonary manifestation due to all previous reasons, especially a lower gene expression of the ACE- 2 receptor. In contrast, adults with severe respiratory failure syndrome due to SARS-CoV-2 infection, who typically deteriorate near one week later of illness onset, have a dysregulation of immune system as opposed to direct cellular injury from viral infection. The immune dysregulation in adults that experienced respiratory distress is characterized by lymphopenia and a sustained production of proinflammatory cytokines, such as TNF- $\alpha$ and IL-6 [83], giving the basis of immunomodulatory therapies like IL-6 blockade at this situation. Although, some suggest more conservative treatments, such as IVIG or even corticosteroids for MIS-C cases, empirical treatment with immunomodulators, such as anakinra or tocilizumab, as a substituted agent in refractory cases are promising [75, 81].

\section{Acute respiratory distress syndrome as another severe presentation}

ARDS is the most severe manifestation of COVID-19 in adults. The survival rate of COVID-19 patients with ARDS who are admitted to an intensive care unit (ICU) is approximately $25 \%$ [18]. In contrast, this situation is uncommon among pediatric patients and is called PARDS $[18,19]$.

\section{Why some children experience more severe illness?}

The reasons that children may experience a severe course have not yet been elucidated. Here, we summarize some possible causes of this discrepancy.

\section{Underlying conditions}

There are some suggestions that several conditions increase the risk of severe disease in children and include hospitalization, mechanical ventilation, congenital heart disease, neurologic, genetic and metabolic conditions [84-86]. Other conditions are related to all ages and include: diabetes mellitus I and II, immunocompromised due to solid organ transplant and other conditions, cerebrovascular accidents, chronic pulmonary disease (e.g., cystic fibrosis, moderate to severe asthma), chronic kidney disease, liver disease, pregnancy, obesity, smocking, sickle cell disease, thalassemia, and hypertension [87]. In two multicenter studies of children admitted to PICU, 40 of 48 and 12 of 17 had an underlying condition [80,81]. In a systematic review of 587 confirmed pediatric patients, $22 \%$ had an underlying condition. Most of them were chronic pulmonary disease $(45 \%)$, congenital heart disease (23\%), immune suppression (12\%), and hematological and oncological conditions (6\%) [20]. 


\section{Immunodeficiency}

It has an important role in development and worse outcome of severity, in both pediatric and adult patients. In the largest ARDS epidemiologic study of adults, $20.8 \%$ and in the pediatric acute respiratory distress syndrome incidence and epidemiology study, $13 \%$ of ARDS cases, had immunosuppression [88, 89].

\section{Weight extremes}

The higher body mass index has been shown to be an independent factor associated with increased risk of ARDS development. As a paradox, the underweight patients with ARDS have higher mortality [90].

\section{Environmental factors}

In adult population, cigarette smoking is associated with ARDS in patients with sepsis [91]. This can be generalized to pediatrics as both active and passive smokers.

\section{Age}

It seems that infants aged less than 1 year are at higher risk of infection and severity [15]. In the largest pediatric population-based study to date with 2143 patients, the proportion of severe and critical cases was $10.6 \%$ under 1 year, suggesting the higher risk of severe respiratory failure in infants. In addition to smaller airways, both immaturity of respiratory tract and immune system, alongside with relatively lower trained immunity might contributed to this severity $[16,68$, 92].

\section{Race and ethnicity}

Pediatric studies have not always observed a marked association between ARDS and both race and ethnicity, perhaps due to limited sample size. However, African and Hispanic ethnicity appears to be major risks in MIS-C patients [81].

\section{Genetic factors}

\section{Genetic factors associated to acute respiratory distress syndrome}

To date, several single-nucleotide polymorphisms have been identified by the increased risk of ARDS. The most significant variants are surfactant protein-B, ACE, angiotensin-2, and IL-1R antagonist [93]. The endothelial protein $\mathrm{C}$ receptor and thrombomodulin genes were independent factors associated with mortality [94]. IL-1 pathway cytokines are associated with ARDS risk, although this association has not been found in PARDS studies [95]. The regulatory gene arylsulfatase-D was linked in 22 and $4 \%$ of ARDS cases and controls, respectively. Also, XK Kell blood group complex membr-3 was present in a minor allele frequency of 37 and $4 \%$ of ARDS cases and controls, respectively [96]. It has been shown that there are five variants of cystic fibrosis transmembrane conductance regulator splicing factor gens that independently are associated with PARDS in African American children without cystic fibrosis. Another variant also was identified in Caucasian children with cystic fibrosis, without higher risk of ARDS development [97].

\section{Genetic factors associated to other severe types and multisystem inflammatory syndrome}

Interestingly, the cluster of MIS-C patients in some countries after the peak incidence of coronavirus infection among adults by approximately one month and in contrast no statistically significant difference in Japan and Korea, suggest a genetic and ethnicity background for these severe cases [22]. However, at this time the extent to which genetics impacts the development of MIS-C is unclear. Considering the implications of host genes in the cell entry and replication of SARS-CoV-2 and in mounting the immune system response, it appears that several genes might be involved. The variations within $A C E-2$ gene, the human leukocyte antigen locus, and the genes regulating Toll-like receptor and complement pathways seem to influence susceptibility and subsequently the severity of COVID-19 [98]. In addition to possible involvement of several other genes (e.g., ABO blood type and Mediterranean fever gene) [99], genetic variations in these gateways might be influenced by the societies geographically. Using a combinational analysis approach, Taylor and colleagues identified 68 protein-coding genes that were highly associated with severe COVID-19 [100]. Ouyang et al. revealed that the number of differentially expressed genes $(D E G s)$ increased by disease progression and decreased after initial treatment. All down-regulated DEGs in severe cases mainly involved Th17 activation [101].

\section{Blood group}

Researchers identified the 3 p21.31 gene cluster as a genetic susceptibility locus in severe COVID-19 patients with respiratory failures. The results from comparing 1900 severe COVID-19 patients and 1200 healthy blood donors indicated that people with blood group A had a $45 \%$ higher risk of infection than others. Similarly, they found blood group $\mathrm{O}$ was associated with a lower risk of acquiring COVID-19 [102]. 


\section{Other reasons}

Unexpectedly, some children may have more viral loads without any other reasons. The higher exposure with or without high-risk behavior, alongside the more expression of ACE- 2 receptors due to the less immaturity, a less previous exposure to coronavirus, influenza and other viruses, not getting the flu vaccine and some other vaccines, a less simultaneous presence of other viruses in body, and a more bacterial nasal colonization, all can be generalized as involved factors at this setting. In addition, some children may have a weaker innate response; while the strong innate response can be due to more exposure to previous viruses and many other reasons. They also, may have a relatively greater adaptive response alongside memory cells like adults [30, 90].

\section{Conclusions}

There are several potential reasons that children have relatively milder illness. In addition to a fewer outdoor activity, children have a number of characteristics that protect them against SARS-CoV-2 infection. They have a healthier respiratory machinery alongside a different expression of receptors in the lower respiratory tract. Also, we believe that the collection of immune system specifications including a less vigorous adaptive system beside a preliminary potent innate response, the constitutional higher level of lymphocyte counts, the trained immunity with cross-reactive neutralizing antibodies, the lack effects of aging, and the interaction between the immune system and respiratory tract might be protecting children against SARS-CoV-2 infection. Although, these findings suggest that COVID-19 is less common and somewhat milder in children compared to adults, there are now some reports of children presenting with severe types of infection such as MIS-C. The exact incidence of MIS-C following an asymptomatic or even a mildly symptomatic infection with SARS-CoV-2 is unclear. However, further investigations are needed to explore other possible causes of less severity of SARS-CoV-2 infection in the pediatric population.

Acknowledgements The authors thank the staff and participants of this study for their important contributions.

Author contributions All authors involved in searching process and data collection. SR and PS designed the body of article and wrote the results and conclusions. SR contributed to conceptualization, data curation, formal analysis, funding acquisition, investigation, methodology, project administration, resources, software, supervision, validation, visualization, writing of original draft, review and editing. PS contributed to data curation, formal analysis, investigation, methodology, software, supervision, validation, visualization, writing of original draft, review and editing. PS contributed to resources, validation, and visualization.
SR contributed to investigation, methodology, software, resources, and validation.

Funding None.

\section{Compliance with ethical standards}

Ethical approval Not applicable.

Conflict of interest The authors declare no conflict of interest related to this work. No financial or nonfinancial benefits have been received or will be received from any party related directly or indirectly to the subject of this article.

\section{References}

1. WHO. WHO Director-General's opening remarks at the media briefing on COVID-19. https://www.who.int/dg/speeches/detail/ who-director-general-s-opening-remarks-at-the-media-briefingon-covid-19---11-march-2020. Accessed 11 Mar 2020.

2. Wu Z, McGoogan JM. Characteristics of and important lessons from the coronavirus disease 2019 (COVID-19) outbreak in China: summary of a report of 72314 cases from the Chinese Center for Disease Control and Prevention. JAMA. 2020;323:1239-42.

3. Yang X, Yu Y, Xu J, Shu H, Liu H, Wu Y, et al. Clinical course and outcomes of critically ill patients with SARS-CoV-2 pneumonia in Wuhan, China: a single-centered, retrospective, observational study. Lancet Respir Med. 2020;8:475-81.

4. Hosseininasab A, Sinaei R, Bahman-Bijari B, Moeinaldini R. Nasal colonization rate of community and hospital acquired methicillin resistant Staphylococcus aureus in hospitalized children. J Kerman Univ Med Sci. 2013;20:52-62 (in Iranian).

5. Wang D, Hu B, Hu C, Zhu F, Liu X, Zhang J, et al. Clinical characteristics of 138 hospitalized patients with 2019 novel coronavirus-infected pneumonia in Wuhan. China JAMA. 2020;323:1061-9.

6. Chan JFW, Yuan S, Kok KH, To KKW, Chu H, Yang J, et al. A familial cluster of pneumonia associated with the 2019 novel coronavirus indicating person-to-person transmission: a study of a family cluster. Lancet. 2020;395:514-23.

7. Shen K, Yang Y, Wang T, Zhao D, Jiang Y, Jin R, et al. Diagnosis, treatment, and prevention of 2019 novel coronavirus infection in children: experts' consensus statement. World J Pediatr. 2020;16:223-31.

8. The Novel Coronavirus Pneumonia Emergency Response Epidemiology Team. The epidemiological characteristics of an outbreak of 2019 novel coronavirus diseases (COVID-19)—China, 2020. China CDC Weekly. 2020;2:113-22.

9. Livingston E, Bucher K. Coronavirus disease 2019 (COVID-19) in Italy. JAMA. 2020;323:1335.

10. Qiu H, Wu J, Hong L, Luo Y, Song Q, Chen D. Clinical and epidemiological features of 36 children with coronavirus disease 2019 (COVID-19) in Zhejiang, China: an observational cohort study. Lancet Infect Dis. 2020;20:689-96.

11. Lee PI, Hu YL, Chen PY, Huang YC, Hsueh PR. Are children less susceptible to COVID-19? J Microbiol Immunol Infect. 2020;53:371-2.

12. Gudbjartsson DF, Helgason A, Jonsson H, Magnusson OT, Melsted P, Norddahl GL, et al. Spread of SARS-CoV-2 in the Icelandic population. N Engl J Med. 2020;382:2302-15. 
13. Jing QL, Liu MJ, Zhang ZB, Fang LQ, Yuan J, Zhang AR, et al. Household secondary attack rate of COVID-19 and associated determinants in Guangzhou, China: a retrospective cohort study. Lancet Infect Dis. 2020. https://doi.org/10.1016/S1473 -3099(20)30471-0.

14. NCIRS. Report: COVID-19 in schools-the experience in NSW. https://www.ncirs.org.au/report-covid-19-schools-experience -nsw. Accessed 26 Apr 2020.

15. CDC COVID-19 Response Team. Coronavirus disease 2019 in children-United States, February 12-April 2, 2020. MMWR Morb Mortal Wkly Rep. 2020;69:422-6.

16. Dong Y, Mo X, Hu Y, Qi X, Jiang F, Jiang Z, et al. Epidemiological characteristics of 2143 pediatric patients with 2019 coronavirus disease in China. Pediatrics. 2020;145:e20200702.

17. Lu X, Zhang L, Du H, Zhang J, Li YY, Qu J, et al. SARS-CoV-2 infection in children. N Engl J Med. 2020;382:1663-5.

18. Diorio C, Henrickson SE, Vella LA, McNerney KO, Chase JM, Burudpakdee C, et al. Multisystem inflammatory syndrome in children and COVID-19 are distinct presentations of SARSCoV-2. J Clin Invest. 2020. https://doi.org/10.1172/JCI140970.

19. Weisberg SP, Connors T, Zhu Y, Baldwin M, Lin WH, Wontakal $\mathrm{S}$, et al. Antibody responses to SARS-CoV2 are distinct in children with MIS-C compared to adults with COVID-19. medRxiv. 2020. https://doi.org/10.1101/2020.07.12.20151068.

20. Liguoro I, Pilotto C, Bonanni M, Ferrari ME, Pusiol A, Nocerino A, et al. SARS-COV-2 infection in children and newborns: a systematic review. Eur J Pediatr. 2020;179:1029-46.

21. Feldstein LR, Rose EB, Horwitz SM, Collins JP, Newhams MM, Son MB, et al. Multisystem inflammatory syndrome in US children and adolescents. N Engl J Med. 2020;383:334-46.

22. Nakra NA, Blumberg DA, Herrera-Guerra A, Lakshminrusimha S. Multi-system inflammatory syndrome in children (MIS-C) following SARS-CoV-2 infection: review of clinical presentation, hypothetical pathogenesis, and proposed management. Children (Basel). 2020;7:69.

23. Sinaei R, Pezeshki S, Sinaei R, Shiari R, Yeganeh MH, Parvaresh $\mathrm{S}$, et al. Post nCoV-2 limping child: report of two cases and a rapid review. Pediatr Rheumatol. 2020. https://doi.org/10.21203 /rs.3.rs-59943/v1

24. Henry BM, Lippi G, Plebani M. Laboratory abnormalities in children with novel coronavirus disease 2019. Clin Chem Lab Med. 2020;58:1135-8.

25. Huang C, Wang Y, Li X, Ren L, Zhao J, Hu Y, et al. Clinical features of patients infected with 2019 novel coronavirus in Wuhan. China Lancet. 2020;395:497-506.

26. Cao Q, Chen YC, Chen CL, Chiu CH. SARS-CoV-2 infection in children: transmission dynamics and clinical characteristics. J Formos Med Assoc. 2020;119:670-3.

27. Xie Z. Pay attention to SARS-CoV-2 infection in children. Pediatr Investig. 2020;4:1-4.

28. Mehta P, McAuley DF, Brown M, Sanchez E, Tattersall RS, Manson JJ, et al. COVID-19: consider cytokine storm syndromes and immunosuppression. Lancet. 2020;395:1033-4.

29. Ludvigsson JF. Systematic review of COVID-19 in children show milder cases and a better prognosis than adults. Acta Paediatr. 2020;109:1088-95.

30. Pandit K, Gupta S, Sharma AG. Clinico-pathogenesis of COVID19 in children. Indian J Biochem Bio. 2020;57:264-9.

31. Jeljeli M, Guérin-El Khourouj V, Pédron B, Gressens P, Sibony $\mathrm{O}$, Sterkers G. Ontogeny of cytokine responses to PHA from birth to adulthood. Pediat Res. 2019;86:63-70.

32. Schouten LR, van Kaam AH, Kohse F, Veltkamp F, Bos LD, de Beer FM, et al. Age-dependent differences in pulmonary host responses in ARDS: a prospective observational cohort study. Ann Intensive Care. 2019;9:55.
33. Pawelec G. Age and immunity: what is "immunosenescence"? Exp Gerontol. 2018;105:4-9.

34. Fulop T, Larbi A, Dupuis G, Le Page A, Frost EH, Cohen AA, et al. Immunosenescence and inflamm-aging as two sides of the same coin: friends or foes? Front Immunol. 2018;8:1960.

35. Fali $\mathrm{T}$, Vallet H, Sauce D. Impact of stress on aged immune system compartments: overview from fundamental to clinical data. Exp Gerontol. 2018;105:19-26.

36. Zlamy M, Almanzar G, Parson W, Schmidt C, Leierer J, Weinberger B, et al. Efforts of the human immune system to maintain the peripheral CD8+ T cell compartment after childhood thymectomy. Immun Ageing. 2016;13:3.

37. Britanova OV, Putintseva EV, Shugay M, Merzlyak EM, Turchaninova MA, Staroverov DB, et al. Age-related decrease in TCR repertoire diversity measured with deep and normalized sequence profiling. J Immunol. 2014;192:2689-98.

38. Harley CB, Futcher AB, Greider CW. Telomeres shorten during ageing of human fibroblasts. Nature. 1990;345:458-60.

39. Cohen S, Janicki-Deverts D, Turner RB, Casselbrant ML, LiKorotky HS, Epel ES, et al. Association between telomere length and experimentally induced upper respiratory viral infection in healthy adults. JAMA. 2013;309:699-705.

40. Zhu H, Wang X, Gutin B, Davis CL, Keeton D, Thomas J, et al. Leukocyte telomere length in healthy Caucasian and AfricanAmerican adolescents: relationships with race, sex, adiposity, adipokines, and physical activity. J Pediatr. 2011;158:215-20.

41. Wenham C, Smith J, Morgan R, Gender and COVID-19 Working Group. COVID-19: the gendered impacts of the outbreak. Lancet. 2020;395:846-8.

42. Cristiani L, Mancino E, Matera L, Nenna R, Pierangeli A, Scagnolari $\mathrm{C}$, et al. Will children reveal their secret? The coronavirus dilemma. Eur Respir J. 2020;55:2000749.

43. Wong HR, Freishtat RJ, Monaco M, Odoms K, Shanley TP. Leukocyte subset-derived genome-wide expression profiles in pediatric septic shock. Pediatr Crit Care Med. 2010;11:349-55.

44. Jiang M, Guo Y, Luo Q, Huang Z, Zhao R, Liu S, et al. T cell subset counts in peripheral blood can be used as discriminatory biomarkers for diagnosis and severity prediction of COVID- 19 . J Infect Dis. 2020;222:198-202.

45. Soy M, Keser G, Atagündüz P, Tabak F, Atagündüz I, Kayhan S. Cytokine storm in COVID-19: pathogenesis and overview of anti-inflammatory agents used in treatment. Clin Rheumatol. 2020;39:2085-94.

46. Warimwe GM, Murungi LM, Kamuyu G, Nyangweso GM, Wambua J, Naranbhai V, et al. The ratio of monocytes to lymphocytes in peripheral blood correlates with increased susceptibility to clinical malaria in Kenyan children. PLoS One. 2013;8:e57320.

47. Hossny E, El-Owaidy R. COVID-19 in children: current data and future perspectives. Egypt J Pediatr Allergy Immunol. 2020;18:3-9.

48. Palm NW, Medzhitov R. Not so fast: adaptive suppression of innate immunity. Nat Med. 2007;13:1142-4.

49. Wynn JL, Cvijanovich NZ, Allen GL, Thomas NJ, Freishtat RJ, Anas N, et al. The influence of developmental age on the early transcriptomic response of children with septic shock. Mol Med. 2011;17:1146-56.

50. Orange JS, Du W, Falsey AR. Therapeutic immunoglobulin selected for high antibody titer to RSV also contains high antibody titers to other respiratory viruses. Front Immunol. 2015;6:431.

51. Mi B, Chen L, Panayi AC, Xiong Y, Liu G. Serum Mycoplasma pneumoniae IgG in COVID-19: aprotective factor. medRxiv. 2020. https://doi.org/10.1101/2020.04.12.20060079.

52. Gokce S, Kurugol Z, Cerit Z, Cicek C. The effect of respiratory syncytial virus on the severity of acute bronchiolitis in 
hospitalized infants: a prospective study from Turkey. Iran J Pediatr. 2018. https://doi.org/10.5812/ijp.61034.

53. Meyer Sauteur PM, Unger WW, Nadal D, Berger C, Vink C, van Rossum AMC. Infection with and carriage of Mycoplasma pneumoniae in children. Front Microbiol. 2016;7:329.

54. Gadsby NJ, Reynolds AJ, McMenamin J, Gunson RN, McDonagh S, Molyneaux PJ, et al. Increased reports of Mycoplasma pneumoniae from laboratories in Scotland in 2010 and 2011impact of the epidemic in infants. Euro Surveill. 2012;17:20110.

55. Hardelid P, Verfuerden M, McMenamin J, Smyth RL, Gilbert R. The contribution of child, family and health service factors to respiratory syncytial virus (RSV) hospital admissions in the first 3 years of life: birth cohort study in Scotland, 2009 to 2015. Euro Surveill. 2019;24:1800046.

56. Miller A, Reandelar MJ, Fasciglione K, Roumenova V, Li Y, Otazu GH. Correlation between universal BCG vaccination policy and reduced morbidity and mortality for COVID19: an epidemiological study. medRxiv. 2020. https://doi. org/10.1101/2020.03.24.20042937.

57. Myśliwska J, Trzonkowski P, Szmit E, Brydak LB, Machała M, Myśliwski A. Immunomodulating effect of influenza vaccination in the elderly differing in health status. Exp Gerontol. 2004;39:1447-588.

58. Franklin R, Young A, Neumann B, Fernandez R, Joannides A, Reyahi A, et al. Homologous protein domains in SARS-CoV-2 and measles, mumps and rubella viruses: preliminary evidence that MMR vaccine might provide protection against COVID-19. medRxiv. 2020. https://doi.org/10.1101/2020.04.10.20053207.

59. Hanker VS. Measles immunization: worth considering containment strategy for SARS-CoV-2 global outbreak. Indian Pediatr. 2020;57:380.

60. Molloy EJ, Bearer CF. COVID-19 in children and altered inflammatory responses. Pediatr Res. 2020;88:340-1.

61. Zhu L, Lu X, Chen L. Possible causes for decreased susceptibility of children to coronavirus. Pediatr Res. 2020;88:342.

62. Rodrigues Prestes TR, Rocha NP, Miranda AS, Teixeira AL, Simoes-E-Silva AC. The anti-inflammatory potential of ACE2/ angiotensin-(1-7)/mas receptor axis: evidence from basic and clinical research. Curr Drug Targets. 2017;18:1301-13.

63. Sodhi CP, Nguyen J, Yamaguchi Y, Werts AD, Lu P, Ladd $\mathrm{MR}$, et al. A dynamic variation of pulmonary ACE2 is required to modulate neutrophilic inflammation in response to Pseudomonas aeruginosa lung infection in mice. J Immunol. 2019;203:3000-122.

64. Yoon HE, Kim EN, Kim MY, Lim JH, Jang IA, Ban TH, et al. Age-associated changes in the vascular renin-angiotensin system in mice. Oxidative medicine and cellular longevity. Oxid Med Cell Longev. 2016;2016:6731093.

65. Attili AR, Nebbia P, Bellato A, Galosi L, Papeschi C, Rossi G, et al. The effect of age and sampling site on the outcome of Staphylococcus aureus infection in a rabbit (oryctolagus cuniculus) farm in Italy. Animals (Basel). 2020;10:774.

66. Nickbakhsh S, Mair C, Matthews L, Reeve R, Johnson PCD, Thorburn F, et al. Virus-virus interactions impact the population dynamics of influenza and the common cold. Proc Natl Acad Sci U S A. 2019;116:27142-50.

67. Liu Y, Yan LM, Wan L, Xiang TX, Le A, Liu JM, et al. Viral dynamics in mild and severe cases of COVID-19. Lancet Infect Dis. 2020;20:656-7.

68. Kelvin AA, Halperin S. COVID-19 in children: the link in the transmission chain. Lancet Infect Dis. 2020;20:633-4.

69. Jubelt B, Narayan O, Johnson RT. Pathogenesis of human poliovirus infection in mice. II. Age-dependency of paralysis. J Neuropathol Exp Neurol. 1980;39:149-59.

70. Marim F, Karadogan D, Eyuboglu TS, Emiralioglu N, Gurkan $\mathrm{CG}$, Toreyin $\mathrm{ZN}$, et al. Lessons learned so far from the pandemic: a review on pregnants and neonates with COVID-19. Eurasian J Med. 2020;52:202-10.

71. Lu Q, Shi Y. Coronavirus disease (COVID-19) and neonate: what neonatologist need to know. J Med Virol. 2020;92:564-7.

72. Levy O. Innate immunity of the newborn: basic mechanisms and clinical correlates. Nat Rev Immunol. 2007;7:379-90.

73. Fornari F. Vertical transmission of Covid-19-a systematic review. J Pediatr Perinatol Child Health. 2020;4:7-13.

74. Dong L, Tian J, He S, Zhu C, Wang J, Liu C, et al. Possible vertical transmission of SARS-CoV-2 from an infected mother to her newborn. JAMA. 2020;323:1846-8.

75. Zeng H, Xu C, Fan J, Tang Y, Deng Q, Zhang W, et al. Antibodies in infants born to mothers with COVID-19 pneumonia. JAMA. 2020;323:1848-9.

76. Zeng L, Xia S, Yuan W, Yan K, Xiao F, Shao J, et al. Neonatal early-onset infection with SARS-CoV-2 in 33 neonates born to mothers with COVID-19 in Wuhan. China. JAMA Pediatr. 2020;174:722-5.

77. Koné-Paut I, Cimaz R. Is it Kawasaki shock syndrome, Kawasaki-like disease or pediatric inflammatory multisystem disease? The importance of semantic in the era of COVID-19 pandemic. RMD Open. 2020;6:e001333.

78. Dufort EM, Koumans EH, Chow EJ, Rosenthal EM, Muse A, Rowlands J, et al. Multisystem inflammatory syndrome in children in New York State. N Engl J Med. 2020;383:347-58.

79. Park A, Iwasaki A. Type I and type III interferons-induction, signaling, evasion, and application to combat COVID-19. Cell Host Microbe. 2020;27:870-8.

80. Blanco-Melo D, Nilsson-Payant BE, Liu WC, Uhl S, Hoagland $\mathrm{D}, \mathrm{M} \varnothing l$ ler R, et al. Imbalanced host response to SARS-CoV-2 drives development of COVID-19. Cell. 2020;181:1036-45.e9.

81. Gruber C, Patel R, Trachman R, Lepow L, Amanat F, Krammer $\mathrm{F}$, et al. Mapping systemic inflammation and antibody responses in multisystem inflammatory syndrome in children (MIS-C). medRxiv. 2020. https://doi.org/10.1101/2020.07.04.20142752.

82. Stringer E, Yeung RSM. Pathogenesis of Kawasaki disease: the central role of TNF- $\alpha$. Future Rheumatol. 2008;3:69-77.

83. Giamarellos-Bourboulis EJ, Netea MG, Rovina N, Akinosoglou $\mathrm{K}$, Antoniadou A, Antonakos N, et al. Complex immune dysregulation in COVID-19 patients with severe respiratory failure. Cell Host Microbe. 2020;27:992-1000.e3.

84. Stokes EK, Zambrano LD, Anderson KN, Marder EP, Raz KM, Felix SE, et al. Coronavirus disease 2019 case surveillanceUnited States, January 22-May 30, 2020. MMWR Morb Mortal Wkly Rep. 2020;69:759-65.

85. González-Dambrauskas S, Vásquez-Hoyos P, Camporesi A, Díaz-Rubio F, Piñeres-Olave BE, Fernández-Sarmiento J, et al. Pediatric critical care and COVID-19. Pediatrics. 2020. https:// doi.org/10.1542/peds.2020-1766.

86. Shekerdemian LS, Mahmood NR, Wolfe KK, Riggs BJ, Ross CE, McKiernan CA, et al. Characteristics and outcomes of children with coronavirus disease 2019 (COVID-19) infection admitted to US and Canadian pediatric intensive care units. JAMA Pediatr. 2020. https://doi.org/10.1001/jamapediatrics.2020.1948.

87. United States Centers for Disease Control and Prevention. People who are at increased risk for severe illness. https://www.cdc.gov/ coronavirus/2019-ncov/need-extra-precautions/people-at-incre ased-risk.html. Accessed 30 June 2020.

88. Bellani G, Laffey JG, Pham T, Fan E, Brochard L, Esteban A, et al. Epidemiology, patterns of care, and mortality for patients with acute respiratory distress syndrome in intensive care units in 50 countries. JAMA. 2016;315:788-800.

89. Khemani RG, Smith L, Lopez-Fernandez YM, Kwok J, Morzov $\mathrm{R}$, Klein MJ, et al. Paediatric acute respiratory distress syndrome incidence and epidemiology (PARDIE): an international, observational study. Lancet Respir Med. 2019;7:115-28. 
90. Kohne JG, Flori HR. Risk factors and etiologies of pediatric acute respiratory distress syndrome. Pediatric acute respiratory distress syndrome, a clinical guide. Cham: Springer; 2020. p. 33-46.

91. Calfee CS, Matthay MA, Kangelaris KN, Siew ED, Janz DR, Bernard GR, et al. Cigarette smoke exposure and the acute respiratory distress syndrome. Crit Care Med. 2015;43:1790-7.

92. Tregoning JS, Schwarze J. Respiratory viral infections in infants: causes, clinical symptoms, virology, and immunology. Clin Microbiol Rev. 2010;23:74-98.

93. Reilly JP, Christie JD, Meyer NJ. Fifty years of research in ARDS. Genomic contributions and opportunities. Am J Respir Crit Care Med. 2017;196:1113-21.

94. Sapru A, Liu KD, Wiemels J, Hansen H, Pawlikowska L, Poon $\mathrm{A}$, et al. Association of common genetic variation in the protein $\mathrm{C}$ pathway genes with clinical outcomes in acute respiratory distress syndrome. Crit Care. 2016;20:151.

95. Dahmer MK, Quasney MW, Sapru A, Gildengorin G, Curley MA, Matthay MAQ, et al. Interleukin-1 receptor antagonist is associated with pediatric acute respiratory distress syndrome and worse outcomes in children with acute respiratory failure. Pediatr Crit Care Med. 2018;19:930-8.

96. Shortt K, Chaudhary S, Grigoryev D, Heruth DP, Venkitachalam $\mathrm{L}$, Zhang LQ, et al. Identification of novel single nucleotide polymorphisms associated with acute respiratory distress syndrome by exome-seq. PLoS One. 2014;9:e111953.
97. Perez-Marques F, Simpson P, Yan K, Quasney MW, Halligan $\mathrm{N}$, Merchant $\mathrm{D}$, et al. Association of polymorphisms in genes of factors involved in regulation of splicing of cystic fibrosis transmembrane conductance regulator mRNA with acute respiratory distress syndrome in children with pneumonia. Crit Care. 2016;20:281.

98. Debnath M, Banerjee M, Berk M. Genetic gateways to COVID19 infection: implications for risk, severity, and outcomes. FASEB J. 2020. https://doi.org/10.1096/fj.202001115R.

99. Singh U, Wurtele ES. Differential expression of COVID-19-related genes in European Americans and African Americans. bioRxiv. 2020. https://doi.org/10.1101/2020.06.09.143271.

100. Taylor K, Das S, Pearson M, Kozubek J, Pawlowski M, Jensen CE, et al. Analysis of genetic host response risk factors in severe COVID-19 patients. medRxiv. 2020. https://doi. org/10.1101/2020.06.17.20134015.

101. Ouyang Y, Yin J, Wang W, Shi H, Shi Y, Xu B, et al. Down-regulated gene expression spectrum and immune responses changed during the disease progression in COVID-19 patients. Clin Infect Dis. 2020. https://doi.org/10.1093/cid/ciaa462.

102. Ellinghaus D, Degenhardt F, Bujanda L, Buti M, Albillos A, Invernizzi $\mathrm{P}$, et al. Genomewide association study of severe Covid-19 with respiratory failure. N Engl J Med. 2020. https:// doi.org/10.1056/NEJMoa2020283.

Publisher's Note Springer Nature remains neutral with regard to jurisdictional claims in published maps and institutional affiliations. 